\title{
Reasons given for being unemployed and the job search progress
}

\author{
Beryl Hesketh and George Shouksmith*
}

This paper examines whether the reasons given for being unemployed and for getting a previous job differentiate between those who later obtain jobs and those who remain unemployed. Initial interviews were carried out with 82 registered unemployed, 51 of whom participated in a follow-up one month later. Those who initially blamed their unemployment on a lack of jobs and who thought that success in the past was due to their own effort, were found to be more likely to obtain jobs. The dilemma of an active job search strategy which produces feelings of low well-being, but also a greater likelihood of obtaining work is discussed. Suggestions are given for ways of handling the conflict.

The need to understand the different responses of subjects to being unemployed, together with the current public debate about the causes of unemployment, were the major motivations for the research reported in this article. Certain sectors of society blame the unemployed for their own condition. Others blame the system, the Government or the economy. It seemed important therefore, to investigate what reasons the unemployed themselves offered for their difficulty in getting jobs, and what the consequences were of their explanations. Attribution theory, one of the major theoretical approaches in modern social psychology (Kelley and Michela, 1980), and Weiner's (1974) causal classification system were used as the explanatory basis for the research.

Attribution theory developed from the work of Heider (1958) who discussed the ways in which ordinary people understand their own behaviour by deciding what causes it. Subsequently, Weiner (1974) suggested a two-dimensional classification of causes. Causes can be found within the person or within the situation (internal-external dimension) and they can also be seen as unchanging or transient (stable-unstable dimension). "Ability" can be thought of as an internal stable factor, "task difficulty" an external stable factor, "effort" an internal unstable factor and "luck" an external unstable factor.

Most people make different causal explanations following their successes and failures. Success is seen as being due to internal factors such as effort or ability, while failure is more likely to be blamed on external factors such as task difficulty or bad luck (Zuckerman, 1979). Weiner (1974) reports that there are individual differences in these biases which relate to motivation. It is reasonable, therefore, to hypothesise that the causal explanations offered by the unemployed will differentiate those subjects who succeed in obtaining work from those who remain unemployed. It is also anticipated that demographic variables and job-search behaviours will discriminate between the groups.

* Department of Psychology, Massey University.

The results reported in this article are part of a larger study investigating a broad range of psychological aspects of unemployment in the context of a validation of Kelley's (1973) covariation attribution theory. Information on other aspects of the research can be obtained from the first author. The Department of Labour is gratefully acknowledged for co-operating in asking the registered unemployed to volunteer for this research. 


\section{Method}

\section{Subjects}

The subjects were obtained with the co-operation of the Department of Labour (Although certain restrictions were placed on the research.) A total of 184 newly-registered unemployed were approached by the duty employment officer, 128 of whom volunteered (70 percent), while 82 were finally interviewed ( 45 percent of original subjects approached or 64 percent of those volunteering). Six of the subjects who did not show for their interviews telephoned to cancel their appointments for various reasons.

Of the 82 registered unemployed in the final sample, follow-up interviews were completed with 51 ( 62 percent) one month later. Of the remainder, nine had left town, ten had not provided a correct follow up address, three were working and preferred not to be interviewed, five did not show for the interview, and the reason was unknown for four of the subjects. This information was gleaned either at the first interview or from family, flatmates or the respondents themselves when telephoning to arrange the follow up interviews. Numerous attempts were made to contact the respondents, including visits to the addresses given.

While the response rate is low, respondents were being asked to travel into the centre of the city at their own expense for the interviews the day after they registered and again one month later. This procedure was necessary so as not to interfere with visits to the Department of Social Welfare, to ensure independence from the Department of Labour and to obtain a suitable venue free from the distractions and family influences of the respondents' homes. As the primary aim of the study was to test hypotheses, not to undertake a survey of the unemployed, the quality of the data obtained from the sample was more important than its representative nature.

A short questionnaire completed by all who were approached by the duty employment officer provided a basis for assessing bias in the sample. Those with higher qualifications were over-represented in the interviewed sample, and the average age of the females interviewed was higher than those not interviewed.

Comparisons between the sample for whom a second interview was completed $(N=51)$ and those who were only interviewed once $(\mathrm{N}=31)$ revealed a socio-economic bias, fewer respondents with a lower socio-economic status being included in the follow-up sample. This could be reflecting the lack of permanent address which hampered follow-up work and which may well be more prevalent among the lower socio-economic status groups.

No other biases were detected in those who showed for the first interview or in those who were followed up (see Appendix for details).

The results reported here focus in particular on the 51 ( 24 females and 27 males) respondents with whom follow up interviews were completed. These respondents had an average age of 24 ranging from 15 to 55 years, 23 had no qualifications, three had some School Certificate passes, and 25 had University Entrance or a higher qualification including six with a university degree. The majority of the respondents (38) had never been married, five were married while eight were separated or divorced. Despite being newly registered, 17 of the respondents had been unemployed for more than a month at the time of the first interview. At the time of the second interview 24 respondents were working and 27 were still unemployed.

\section{Procedure and Instruments}

All interviews were carried out by the first author between April and September 1981 on the day after the respondents first registered and again one month later.

Data was collected by means of an interview because of a suspected low reading level and because it was felt that the sensitive nature of some of the questions required a more 
responsive medium than a questionnaire. The interview protocol involved a combination of structured questions with precoded responses on cards together with an unstructured phase allowing for in-depth exploration of issues associated with unemployment.

Questions covered a range of demographic variables including the number of jobs applied for and the number of job interviews attended. As many respondents were young the socio economic status of the family breadwinner during formative years was used.

The structured questions about the causes for success and failure in job seeking were based on the attribution items widely quoted in the literature (Elig and Frieze, 1979) and on Weiner's (1974) two-by-two classification given in Figure 1.

Figure 1: Weiner's (1974) causal classification illustrated with the examples used in this research for success $(S)$ and failure $(F)$

Internal External

\begin{tabular}{|c|c|c|}
\hline \multirow[b]{2}{*}{ Stable } & - lack of ability or skill (F) & - jobs are too difficult to get $(F)$ \\
\hline & $\begin{array}{l}\text { - you had the ability or skill } \\
\text { for the job (S) }\end{array}$ & - jobs like that were easy to get (S) \\
\hline \multirow{2}{*}{ Unstable } & $\begin{array}{l}\text { - you haven't tried hard enough } \\
\text { to get a job yet (F) }\end{array}$ & - bad luck (F) \\
\hline & $\begin{array}{l}\text { - you tried particularly hard for } \\
\text { the job (S) }\end{array}$ & - good luck (S) \\
\hline
\end{tabular}

Respondents were asked to rate the importance of each of the reasons given in Figure 1 by referring to a card with a seven-point scale containing verbal and numerical anchors for each point ranging from extremely unimportant (1) to extremely important (7). The failure question related to the reason for their being unemployed while the success question referred to the reasons for being offered their last job. In addition the responses to an open-ended question regarding the reasons for not having a job (failure) and for obtaining their last job (success) were recorded verbatim.

Life satisfaction measures and a general happiness measure extracted from Warr, Cook and Wall (1979), and the 12-item General Health Questionnaire (GHQ) designed to detect minor psychiatric disorders in a community setting (Goldberg, 1972) were administered during the interview. Banks, Clegg, Jackson, Kemp, Stafford, and Wall (1980) recommend the use of the 12-item version of the GHQ as a measure of negative mental health in occupational studies.

Most of the questions at the follow up interview were the same as those used at the first interview. In addition a simple question asking the respondents to rank order the relative importance of work, family and social aspects of their lives was included.

\section{Results and Discussion}

\section{Perceived Causes for Success and Failure as Predictors of Getting a Job}

In the present research discriminant function analysis was used to assess whether the importance placed on the causes outlined in Figure 1 at the first interview discriminated between those respondents who remained unemployed $(\mathrm{N}=27)$ and those who had obtained a job $(\mathrm{N}=24)$ by the time of the second interview. Discriminant function analysis is a statistical technique for measuring the extent to which a measurement variable dis- 
tinguishes between two groups, or samples. The discriminant function was significant $\left(X^{2}=24.317, \mathrm{DF}=(14), \mathrm{p}<.05\right)$, indicating that the perceived causes at the first interview did predict the outcome of getting a job. Table 1 provides the discriminant function coefficients for each cause, the mean importance rating of the causes for each group, and the $F$ values showing the significance of the difference between these means.

Table 1: Discriminant function coefficients, $F$ values and means for the importance of the perceived causes for success and failure

\begin{tabular}{lcccc}
\hline & $\begin{array}{c}\text { Discriminant } \\
\text { Function } \\
\text { Coefficient }\end{array}$ & F Value & $\begin{array}{c}\text { Mean } \\
\text { Unemployed } \\
\text { Group }\end{array}$ & $\begin{array}{c}\text { Mean } \\
\text { Employed } \\
\text { Group }\end{array}$ \\
\hline $\begin{array}{l}\text { Failure } \\
\text { Task difficulty }\end{array}$ & -.902 & $10.82 * *$ & 4.15 & 5.67 \\
$\quad$ Lack of ability & .036 & 0.051 & 4.26 & 4.38 \\
Bad luck & .441 & 1.553 & 2.81 & 3.46 \\
Lack of effort & & & & 4.58 \\
$\quad$ (trying) & .036 & 0.003 & 4.56 & \\
& & & & \\
Success & .598 & 1.954 & 4.07 & 3.42 \\
Task ease & .388 & 1.472 & 4.77 & 4.17 \\
Ability & .067 & 0.083 & 4.26 & 4.42 \\
Good luck & -.620 & $4.286 *$ & 4.30 & 5.25 \\
Effort (tried) & & & &
\end{tabular}

Notes: (a) $* *=\mathrm{p}<.01, *=\mathrm{p}<.05(\mathrm{df}=1,49)$

(b) Group centroids on the discriminant function: Unemployed group $=0.657$, Employed group $=-0.739$

(c) The group centroid merely represents the most typical location for a subject in the group in question, while the size of the standardised discriminant function coefficients (ignoring sign) points to the relative contribution of the variable. The multivariate nature of discriminant analysis sometimes results in signs which are not easily interpreted, and a clearer picture can be obtained from examining the means of the two groups.

The strongest discriminating variable was the importance placed on "task difficulty" as a reason for their earlier failure to get a job. Those who were working at the time of the second interview blamed task difficulty more than did the group still unemployed. The next highest discriminator, and the only other variable for which a significant difference between the means of the employed and unemployed groups was found, was the importance placed on "effort" for an earlier success. Members of the working group attributed their past success to their own effort more than did those in the group still employed. Those still unemployed attributed past success to the external factor of "task ease" to a greater extent than did the group working, although the $F$ value indicates that the differences between the means was not significant. The working subjects also stressed "bad luck" as a reason for failure more than did those still unemployed. Members of the group who obtained jobs took credit for past success, but blamed past failure on external factors, while the unemployed group did not evidence the same self-oriented bias. 


\section{Demographic Variables and Perceived Causes as Predictors}

In order to assess which of the demographic variables and the causes best discriminated between the two groups, a stepwise discriminant analysis was performed. The predictors were the eight causes used in the previous analysis together with age, years of education, socio economic status, weeks unemployed, number of jobs applied for at time of first interview, and number of job interviews attended.

Table 2: Variables remaining in the stepwise discriminant function analysis (Method $=$ Wilks)

\begin{tabular}{lccc}
\hline Variable & $\begin{array}{c}\text { Discriminant } \\
\text { Function } \\
\text { Coefficient }\end{array}$ & $\begin{array}{c}\text { Mean } \\
\text { Unemployed }\end{array}$ & $\begin{array}{c}\text { Mean } \\
\text { Employed }\end{array}$ \\
\hline $\begin{array}{c}\text { Number of job interviews } \\
\text { attended at time one }\end{array}$ & .703 & 0.444 & 1.667 \\
$\begin{array}{c}\text { Failure attributed to task } \\
\text { difficulty }\end{array}$ & .739 & 4.150 & 5.667 \\
$\begin{array}{c}\text { Success attributed to own } \\
\text { effort }\end{array}$ & .279 & 4.296 & 5.250 \\
\hline
\end{tabular}

Note: Wilks' Lambda was used as a criterion in the step wise discriminant analysis. The group centroid for the unemployed group was -0.713 , while that for the employed group was 0.802 . The discriminant function with these three variables was highly significant $\left(\chi^{2}=22.206, \mathrm{DF}=(3)\right.$, $\mathrm{p}<.0001)$. The number of jobs applied for was removed from the discriminant function after effort as a reason for success was included, indicating that the three remaining variables adequately accounted for the variance embodied in "number of jobs applied for".

The results of this stepwise discriminant analysis, presented in Table 2 reinforce the important discriminating role of the causes perceived to be important by the unemployed at the first interview. Obviously, the number of job interviews attended also discriminates. It is important to get as many job interviews as possible, but a major problem for the unemployed is to remain optimistic, whilst continually being rebuffed in their job search. If they do not remain optimistic then they may well give up the job-search. It would seem from the present study, that those who were successful in the search retained their motivation by blaming their unemployment on the difficulty of the task while recognising that success in the past was due to effort on their part.

\section{Dilemmas Faced by the Unemployed}

Other data from the research suggests that well-being is related to feeling that one has not exhausted all possibilities of getting a job, and the more unsuccessful applications the respondents make, the less they are able to feel that their own effort is worthwhile. That an active yet undiscriminating job-search may not be the panacea some assume, is also supported by O'Brien and Kabanoff (1979) who found that stress was positively correlated with the amount of time spent looking for work. This highlights the dilemma which the unemployed face. To obtain a job they must continue to apply for jobs and hopefully be given interviews, but with increasing numbers of unsuccessful applications it becomes more difficult for some to externalise their failure.

The results from the discriminant analysis also suggest that success has to be attributed 
to one's own efforts, otherwise if unemployed again, one may give up. This presents another dilemma as it is functional to encourage individual initiative in searching for jobs, but if this is done without support during the process, the negative consequences suggested by this research, and by O'Brien and Kabanoff (1979), may follow.

The heavy reliance on "contacts" or the Department of Labour for obtaining jobs does not lend itself to the development of self-reliance and the establishment of a link between one's own effort and success. In response to the open question regarding the reasons for obtaining a job, 25 percent of the respondents said that it was thanks to "contacts". Such a system of job acquisition benefits neither those who obtain the jobs nor those who do not have such "contacts".

\section{Changes Which May Help the Unemployed}

Even with the above dilemmas posed by the research results, practical assistance can be given to the unemployed. The Department of Labour should ensure that its employment service is adequately staffed to allow the employment officers to provide the skilled placement services needed, with a particular emphasis on teaching and encouraging the unemployed to be selective in the jobs for which they apply. No-one should be made to feel guilty because they are not on the streets each day looking for work when suitable jobs are not available. Success is best assured if the search concentrates on appropriate job areas. The task of employment officers is to ensure that their clients search for jobs in the correct areas.

Associated with this is a need for clear job descriptions and personnel specifications; the responsibility to provide these surely lies with employers. If employers were able to specify the functional requirements for a job accurately and if job search skills were developed to ensure that jobs were applied for selectively, then employers would save time and the unemployed would not find themselves involved in the disheartening experience of applying for, or being sent to apply for, jobs clearly not suited to their particular skills.

Self reliance could also be fostered through relaxing the rules surrounding the project work schemes so that individuals can take a more active part in creating jobs for themselves. This is done now by those who know the system, but the understanding should be extended to all, as it is one way of retaining the feasibility of taking credit for success.

Many subjects spoke of the frustration experienced when they received no responses to their enquiries about jobs, or when they never heard about the outcome of an interview. Employers must accept the responsibility of letting applicants know the outcome of the selection decision, and the circumstances surrounding it. If an applicant knew that 30 other people had applied for a job, being turned down would not be so bad, and they might come to expect to apply for about 30 jobs before getting one. If employers are making decisions based on the functional requirements of the job and not on the basis of the age, sex, ethnic origin or personal relationships with family and friends, then describing their decision-making criteria to applicants would be quite acceptable.

In countries where court actions on human rights are more common, employers have already had to accept the need to be more careful about their hiring policies and criteria. In New Zealand, the importance of "contacts" as a basis for obtaining jobs has allowed employers to avoid facing up to this responsibility. However, as unemployment grows, and an increasingly large section of the population are denied the status, security and financial benefits of paid employment, pressure on employers to "put their houses in order" in this respect, will increase.

\section{Work, Unemployment and Well-being}

With the small sample size it was possible to undertake a detailed case analysis of the group of subjects working and those still unemployed which revealed a number of working 
subjects who were extremely dissatisfied with their jobs, and whose general well-being and mental health as measured by the GHQ was low. This was not surprising as only 11 of the 24 subjects working were in full-time permanent positions, one was in a part-time permanent position, three had temporary full-time positions and nine were on Department of Labour job-creation schemes. In addition there was a small group of unemployed subjects who were coping well with being unemployed, a group from whom we should perhaps be prepared to learn. As unemployment grows, enforced leisure time increases and the need for education for leisure time use becomes more important.

There are dangers in having an oversimplified view of work and non work as low wellbeing is not restricted to those who are unemployed. Related to this is the finding that the unemployed subjects ranked work as more important in their lives than did those subjects who were working $\left(X^{2}=6.7, \mathrm{DF}=(2), \mathrm{p}<.05\right)$. When out of work, even a day's work becomes meaningful as illustrated by one respondent who, although assigned to periodic detention as punishment, simply longed for Saturdays when he had something meaningful to do. However, when in a job, particularly an unsatisfactory one, work appears to become less important. Work may be better than non-work, but it is not the whole answer. Feelings of well-being in our society are related in complicated ways to unemployment and employment. A task for the immediate future years appears to be to develop much more sophisticated theories of work and adjustment, applicable to the ills and needs of modern society.

\section{Appendix}

\section{Checks on Bias in Sample}

1. Comparison of subjects interviewed $(\mathrm{N}=82)$ and those approached but not interviewed $(\mathrm{N}=102)$

Sex:

48 males and 34 females were interviewed, 71 males and 31 females declined to be interviewed. No significant sex difference was found. $\left(\chi^{2}=\right.$ $1.99, \mathrm{DF}=(1), \mathrm{NS}$, corrected for continuity).

Age: $\quad$ Fewer young females were interviewed than were not interviewed. $(\mathrm{t}=2.93$, $\mathrm{DF}=(63) \mathrm{p}<.01)$. The age difference for the males was negligible. $(\mathrm{t}=$ $.0007)$.

Education: Three education categories were used: no qualifications, some School Certificate qualifications and University Entrance and above. The qualifications of the interviewed group were higher than those of the noninterviewed group for males $\left(\chi^{2}=15.24, \mathrm{DF}=(2), \mathrm{p}<.01\right)$ and for females $\left(\chi^{2}=8.15, \mathrm{DF}=(2), \mathrm{p}<.05\right)$

(Socio-economic status rating on non-interviewed subjects was not available.)

2. Comparison of subjects followed up $(\mathrm{N}=51)$ with those not followed up $(\mathrm{N}=31)$.

Sex: $\quad$ No significant difference was found. $\left(\chi^{2}=2.55, \mathrm{DF}=(1), \mathrm{NS}\right.$, corrected for continuity).

Age: $\quad$ No significant difference was found. $(\mathrm{t}=.356, \mathrm{DF}=(49), \mathrm{NS})$.

Education: No significant difference was found. $\left(\chi^{2}=1.77, \mathrm{DF}=(2) \mathrm{NS}\right)$.

Socio-economic status: Interviewed subjects had a higher SES than those not interviewed. $\left(\chi^{2}=7.12, \mathrm{DF}=(2), \mathrm{p}<.05\right)$. 


\section{References}

Banks, M.H., Clegg, C.W., Jackson, P.R., Kemp, N.J., Stafford, E.M. and Wall, T.D. (1980) The use of the General Health Questionnaire as an indicator of mental health in occupational studies Journal of occupational psychology 53:187-194.

Elig, T.W. and Frieze, I.H. (1979) Measuring causal attributions for success and failure Journal of personality and social psychology 37(4):621-634.

Goldberg, D. (1972) The detection of psychiatric illness by questionnaire London, Oxford University Press.

Heider, F. (1958) The psychology of interpersonal relations New York, Wiley.

Kelley, H.H. (1973) The process of causal attribution American psychologist 28:107-128

Kelley, H.H. and Michela, J.L. (1980) Attribution theory and research Annual.review of psychology 31:457-501.

O'Brien, E.O. and Kabanoff, B. (1979) Comparisons of unemployed and employed workers on work values, locus of control and health variables Australian psychologist 14(2):
143-154.

Warr, P., Cook, J. and Wall, T. (1979) Scales for the measurement of some work attitudes and aspects of psychological well-being Journal of occupational psychology 52: 129-148.

Weiner, B. (1974) Achievement motiviation and attribution theory Morristown, New Jersey, General Learning Press.

Zuckerman, M. (1979) Attribution of success and failure revisited or: The motivational bias is alive and well in attribution theory Journal of personality $47(2): 245-287$. 